\title{
Occurrence and Toxicity of Hydrocarbon Residues in Crab (Callinectes sapidus) from Contaminated Site
}

\author{
${ }^{1 *}$ OLOLADE I.A; ${ }^{2}$ LAJIDE L; ${ }^{2}$ AMOO I.A \\ ${ }^{1}$ Department of Chemistry and Industrial Chemistry, Adekunle Ajasin University, Akungba-Akoko, Ondo-State, Nigeria. \\ ${ }^{2}$ Department of Chemistry, Federal University of Technology, Akure, Nigeria. \\ *Correspondent author: Ololade I.A. E-mail: Olisa200@vahoo.com. "isaac ayodele" <olisa200@yahoo.com>
}

\begin{abstract}
To elucidate seasonal changes in hydrocarbons including polycyclic aromatic hydrocarbons (PAHs) due to oil spill, tissues of blue crab (Callinectes sapidus) were investigated. Total petroleum hydrocarbons (n-alkanes) concentrations ranged from $0.17-0.32 \mu \mathrm{g} / \mathrm{gdw}$ and $0.28-0.62 \mu \mathrm{g} / \mathrm{gdw}$ during the dry and wet seasons respectively. The tissues accumulate a complex spectrum dominated by heavier hydrocarbons, alkylsubstituted and PAHs. The impact of biogenic contribution through dietary uptake was related to the elevated levels, particularly of the PAHs. Studies of other site specific, resident organism are recommended in order to be able to establish the extent of toxicity. @ JASEM
\end{abstract}

There are volumes of literature and critical reviews on the measurement of hydrocarbons including PAHs and their bio-transformation in biological tissues for health effect monitoring, in sediments and mollusks for environmental monitoring, and foodstuffs for safety reasons (Hair, 1998; William et al., 1997; Stroomberg et al., 2004; Shi et al., 2006). Uptake of hydrocarbons, particularly PAHs compound by aquatic biota is very rapid. Invertebrates, especially mollusks, do not metabolise PAHs as efficiently and may accumulate high tissue concentrations (Eisler, 1987, Varanasi et al, 1989). The PAHs are relatively stable constituent of petroleum and many of these compounds are potentially toxic, caranogenic and mutagenic (Ghauch et al., 2000, Aderemi et al., 2003). Previous studies within the area were conducted with the traditional gravimetric method (Asaolu, 1998). Their result however, revealed high concentrations of gravimetric TPH in the water and more in the sediment which are major means of transfer into crab. As a result of the complex nature

\section{MATERIAL AND METHODS Sampling}

Crab samples were collected at both the dry ad wet seasons, though with more difficulty during the wet season probably due to flooding. Thus, 27-29 crabs were collected in December 2004 while only 16-19 crabs were sampled in May 2005. The samples were packed inside an open-glass container ad brought alive into the laboratory where they are subsequently ad carefully observed externally for obvious abnormalities. Samples were later wrapped in hexane - rinsed aluminium foil and stored at -200C (Albers, 1995)

\section{Sample Preparation and Extraction}

The crab meat was "picked" from the chelipeds and the body. Meat from several crabs was composited until a sufficient quantity of meat was obtained for of hydrocarbons and samples matrices generally, the gas chromatography is often the preferred approach for separation and quantification of compounds. Moreover, in modern toxicology, analytical procedure must only be sensitive but must also highly specific. This is because, in most cases the analytes are known in advance and many other xenobiotics or endogenenous biomolecules may interfere into their detection. The hyphenated technique of gas chromatography mass spectrometry (GC-MS) remains the gold standard in analytical toxicology and in hydrocarbon analysis in environmental samples (Maurer, 2007) including some environmentally important PAHs. The paper reports on the level of petroleum hydrocarbons in Crab (Callinectes sapidus) in selected sites within Ondo costal area of Nigeria. The study serves as an improvement for environmental awareness being the first to be investigated with GC - MS within the ecological zone.

the desired chemical analyses. Efforts were ensured that composite were made from those assumed to e of similar size based o physical examination. Extraction of hydrocarbons and clean-up of biota for gas chromatography analysis involves the use of recent method (Ashok et al., 2004). Approximately $10 \mathrm{~g}$ of the meat was placed into a clean mortar, then ground with pestle with $40 \mathrm{~g}$ of anhydrous sodium sulphate. The samples were extracted in soxhlet apparatus with three aliquots of methylene chloride over 14-16 hrs. Internal standard $(1 \mathrm{~m} 1$ each of n-tetracosane ad pyrene for the aliphatic and aromatic respectively were used). A known amount of this extract was evaporated ad the residue weighed to obtain the total organic extract (TOE). The remaining extracts were eluted through a silica-alumina glass column ad the final extract concentrated to a volume of $5 \mathrm{ml}$ prior to GC measurement.

* Corresponding author: ${ }^{1 *}$ Ololade I.A 
Gas chromatography - mass spectrometric (GC MS) analyses

The capillary gas chromatography - mass spectrometry analysis were performed on a Hewlett Packed (HP) 6890 GC series instrument coupled with a 5975 Hewlett - Packed mass spectrometer (MS). The system control and the data acquisition system were controlled by a MS-DOS compatible work station. One microlitre $(1 \mu \mathrm{l})$ of the worked up sample was injected into the GC instrument using a $10 \mu \mathrm{l}$ syringe size. The gas chromatograph was equipped with a split injector (purge delay of 15 secs, purge flow of $6.8 \mathrm{ml} / \mathrm{min}$; injection temperature $250^{\circ} \mathrm{C}$ and pressure of $2.3 \mathrm{kpa}$ ). The capillary column used was of the Agilent 1909IS - 433 model with dimensions of $30 \mathrm{~m} \times 0.25 \mathrm{~mm}$ ID $\times 0.25 \mu \mathrm{m}$ film thickness of HP5M5 (5\% Phenyl Methyl Siloxane). Helium was used as a carrier gas with initial flow rate of $0.7 \mathrm{~mL} / \mathrm{min}$ and average velocity of $30 \mathrm{~cm} / \mathrm{sec}$, the column was kept at $40^{\circ} \mathrm{C}$ initially, and then programmed to $280^{\circ} \mathrm{C}$ for 48mins. The transfer line to the mass spectrometer was set at $200^{\circ} \mathrm{C}$ with electron energy of $69.9 \mathrm{eV}$. Full scan mass spectra between 35 and $500 \mathrm{~m} / \mathrm{z}$ were acquired once every second. The peaks in the chromatogram were identified by comparison of the retention times and mass spectra data of reference compounds with those in the sample using MS Library Wiley and NIST. The peaks were quantified using the flame ionization detector (FID) through a five point calibration curve.

\section{RESULTS AND DISCUSSION}

The total organic extract which is equivalent to the lipids in crab was very high. The average lipid content was $248.9 \pm 22.4 \mathrm{mg} / \mathrm{kg}$ and $296.1 \pm 19.3$ $\mathrm{mg} / \mathrm{kg}$ during the dry and wet seasons respectively. The high lipid content enhances the chances of absorbing more hydrocarbon molecules, especially those that are not easily degraded or eliminated. Details of the gas chromatograms of hydrocarbons during the dry and wet seasons are presented in Fig.2 and 3 respectively. The mean concentrations of identified n-alkanes are presented in Table 1. In the dry season, the n-alkanes (concentration in brackets) ranged from $\mathrm{n}-\mathrm{C}_{18}-\mathrm{n}-\mathrm{C}_{25} \quad(0.17-0.32 \mu \mathrm{g} / \mathrm{g})$ with average concentrations of $1.23 \mu \mathrm{gg}^{-1}$. For wet season, with much less identified n-alkanes, the concentration ranged from $\mathrm{C}_{17}-\mathrm{C}_{19}(0.28-0.62 \mu \mathrm{g} / \mathrm{g})$ with mean concentration of $1.24 \mu \mathrm{g} / \mathrm{g}$. The mean values of TPH were found not to be significantly different $(\mathrm{P}=0.168)$ for both seasons. Similarly, there was no positive correlation between the TPH of n-alkanes in crab of both season ( $\alpha=0.05 \mathrm{r}=-0.932$ ). Also included in Table 2 are concentrations of some environmentally important PAHs. Other compounds identified with their retention indices are presented in Table 2. The data confirm the presence of some alkylated hydrocarbons, cycloalkanes, PAHs (anthracene, phenanthrene, carbazole, dibenzothiophene, azuleno[2,1-b]thiophene and benz[a]anthracene). Some hetero compounds such as those containing oxygen were also identified.
Table 1: Mean Concentrations $( \pm \mathrm{SD})$ of n-Alkanes and PAHs $(\mu \mathrm{g} / \mathrm{g} \mathrm{dw})$ in Crab

\begin{tabular}{lll}
\hline n-Alkanes & Dry Season & Wet Season \\
\hline Heptadecane & $\mathrm{Nd}$ & $0.28 \pm 0.10$ \\
Octadecane & $0.19 \pm 0.02$ & $0.34 \pm 0.16$ \\
Nonadecane & $0.18 \pm 0.08$ & $0.62 \pm 0.24$ \\
Eicosane & $0.17 \pm 0.03$ & nd \\
Heinecosane & $0.32 \pm 0.11$ & nd \\
Tetracosane & $0.17 \pm 0.08$ & nd \\
Pentacosane & $0.20 \pm 0.04$ & nd \\
Mean & $0.21 \pm 0.06$ & $0.41 \pm 0.18$ \\
$\sum$ (n - alkanes $)$ & 1.23 & 1.24 \\
CPI & 1.32 & 2.65 \\
PAHs & & \\
Anthracene & $53.80 \pm 10.21$ & $85.60 \pm 17.24$ \\
Azuleno[2,1-b]thiophene & $5.47 \pm 2.11$ & nd \\
Carbazole & $0.09 \pm 0.04$ & nd \\
Dibenzothiophene & $0.18 \pm 0.09$ & nd \\
Phenanthrene & $41.56 \pm 9.47$ & $65.89 \pm 15.97$ \\
Mean & $20.22 \pm 25.53$ & $75.75 \pm 13.94$ \\
\hline EPAHs & 101.10 & 151.49 \\
\hline
\end{tabular}

Table 2: Other Compounds Identified with their Retention Index

\begin{tabular}{ll}
\hline Compounds & RT/min \\
\hline 1-Eicosene & 34.306 \\
3-Eicosene & 34.259 \\
1-Heptadecene & 37.970 \\
1-Octadecene & 37.917 \\
Cyclooctacosane & 44.442 \\
Cycloeicosane & 42.669 \\
2-Ehtyl anthracene & 46.528 \\
Z-7-Hexadecanoic acid & 33.360 \\
9-Ethyl-9-heptyl-octadecane & 47.608 \\
3-Methyl-1-phenyl 1H-indene & 45.523 \\
2,6,10,14-Tetramethyl octadecane & 45.977 \\
Cholesta-3,5-diene-7-one & 55.042 \\
10-Heptyl-10-octyl-eicosane & 44.469 \\
\hline Athrone & 33.686 \\
\hline
\end{tabular}




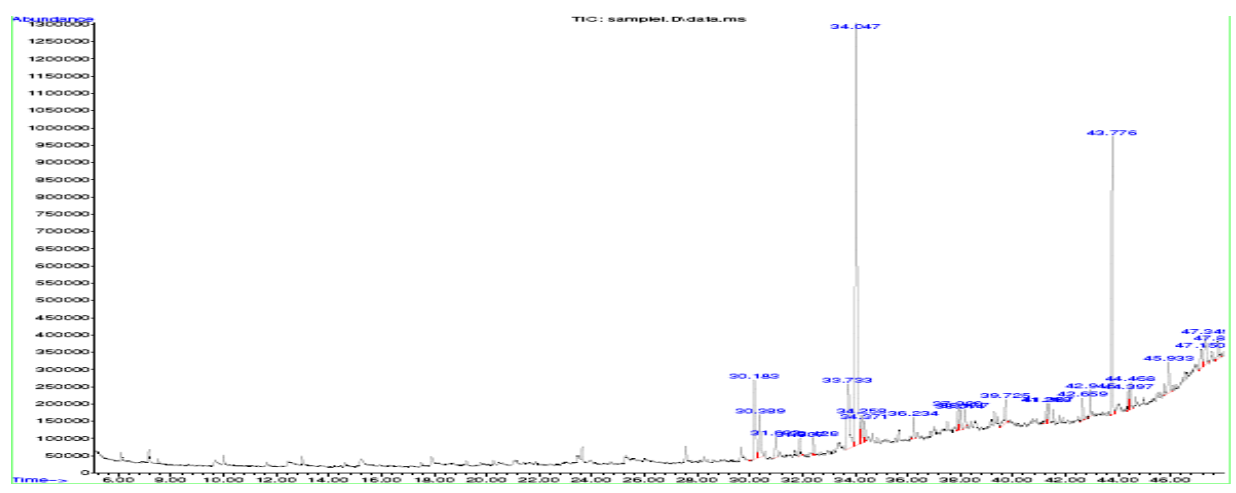

Fig.1: Gas Chromatograms of hydrocarbons in Tissues of Callinectes sapidus during the Dry Season

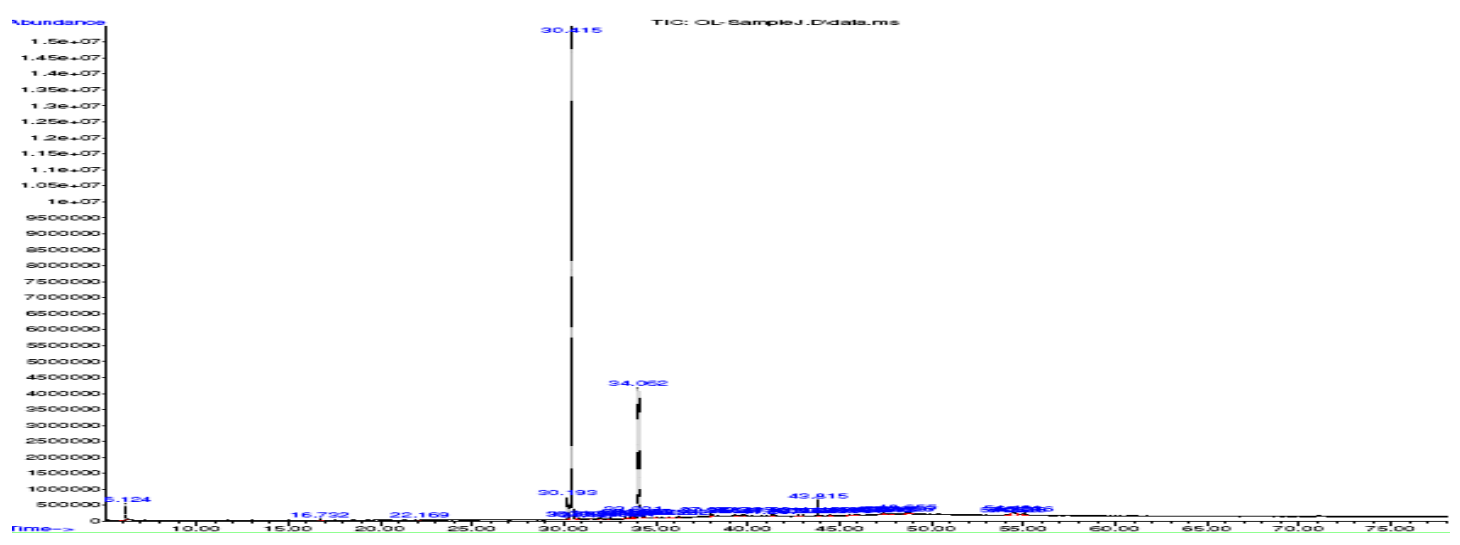

Fig.1: Gas Chromatograms of hydrocarbons in Tissues of Callinectes sapidus during the Wet Season

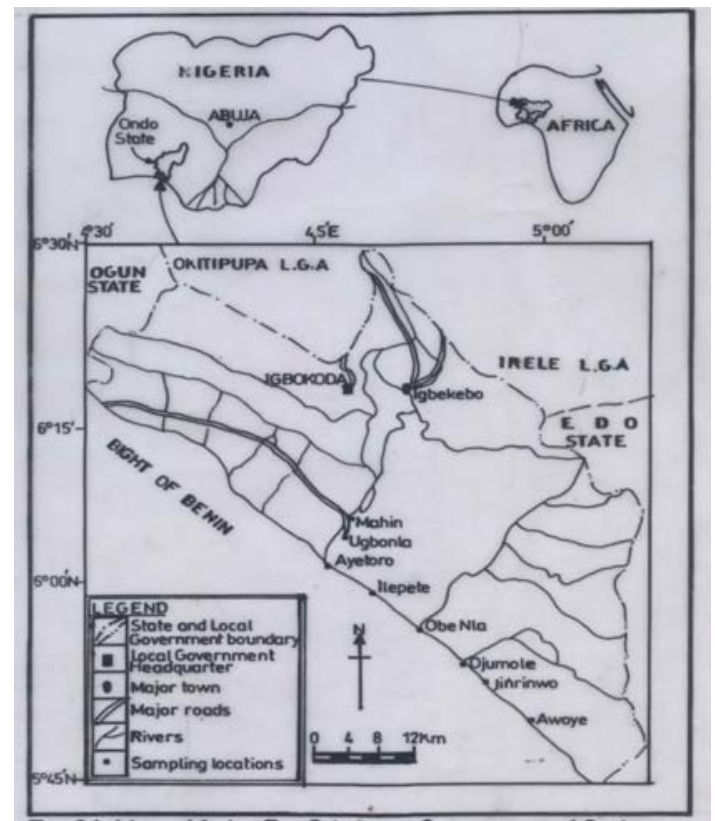

Fig.1. Map of the sampling locations (Inserted is the area map of Nigeria and Africa showing the geographycal locations)

Fig. 1. Map of the sampling locations (inserted is the area map of Nigeria and Africa showing the geographical locations) 
A critical look at Table 1 shows that $n-C_{20}, n-C_{21}, n-$ $\mathrm{C}_{24}$ and $\mathrm{n}-\mathrm{C}_{25}$ are completely absent during the wet season. It is believed that these have been degraded to the lower ones, thus contributed to the increased concentration of $n-C_{17}-n-C_{19}$ during the wet season. Thus, the n-alkanes are presumed unstable within the tissues of crab because there were no serious indications of their retention in the crab tissues. The data in Table 1 and 2 shows that the concentrations of individual hydrocarbons between the two seasons are generally $<1.0 \mu \mathrm{g} / \mathrm{g}$ except for the aromatic compounds which were recorded at a very high concentrations. The complex series of compounds obtained in the study could be due to biotransformation of hydrocarbon in crab. The presence of the mixed function oxygenase (MFO) system, which is commonly found in fish (Rice, 1985; George et al., 1995), has been reported also in crab (Lockhart and Mertner 1991, George et al., 1995). These MFO is responsible for the metabolic modification of foreign organic compound. The hydrocarbon pattern, particularly during the dry season was dominated by the heavier hydrocarbons, alkylsubstituted and PAHs suggesting exposure to highly weathered petroleum mixture. We hypothesized that some of the elevated concentrations may have arisen from contributions of hydrocarbons which are biogenically produced by microorganisms, algae and macrophytes (Eisler, 1987; Sauer and Uhler, 1994). This fact is further complemented by the results of the carbon preference index (CPI) which gave 1.32 and 2.65 for the dry and wet seasons respectively. These CPI values $>1$ suggested the contribution of odd numbered biogenic hydrocarbons in crab.

The concentrations of PAHs are particularly of interest because crabs are a class of delicacy for humans. The very high level, particularly of phenanthrene and anthracene during the wet season demonstrates the persistence of these pollutants in the environment. It further shows that their metabolic/degradative processes within crab are extremely slow and are capable of adsorbing into the tissue of Callinectes sapidus species of crab unlike the other PAHs identified. The increased concentrations of phenanthrene and anthracene during the wet season, also implicates in addition to biogenic source that PAH - containing residue is being introduced into the environment. Considering the aquatic environment under this study, petroleum oil spill has been identified as a major source of PAHs (Eisler, 1987). Apart from the water column and through sediment, dietary uptake is considered an important channel through which these pollutants entered into the crab. This may also be due to the fact that crabs are bottom feeders. In spite of the variability in the n-alkanes at both seasons, the TPH

* Corresponding author: ${ }^{1 *}$ Ololade I.A (n-alkanes) concentrations obtained are similar. For the detectable concentration, hydrocarbon pattern were dominated by the heavier hydrocarbons, suggesting the exposure of the crab to the highly weathered petroleum mixture. The studies showed that biogenic input contributed heavily to the hydrocarbon concentration. The detection and elevated concentration of some PAHs deserves further studies that would establish the extent of toxicity. No doubt, some of the compounds identified are products of hydrocarbon biotransformation.

\section{REFERENCES}

Aderemi, O.O, Olatunde, I.A and Olalekan, S.F (2003): "Isolation and estimation of PAHs in surface run off and sediments". Water,Air,Soil Pollut., 147,245 - 261.

Albers, P.H (1995): "Petroleum and individual polycyclic aromatic hydrocarbon". In: Hoffman, D.J., Rattner, J.A., G.A Burton, Jr., and j. Cairns, Jr., Handbook of Ecotoxicotogy. Lewis Publishers, Boca Raton, Florida, pp 330 - 354.

Asaolu, S.S (1998). "Chemical pollution studies of coastal waters of Ondo state". Ph.D Thesis, Federal University of Technology, Akure,Nigeria.

Ashok, D.D., Bruce, W.D and Amy, M.T. (2004): "Petroleum hydrocarbons in sediments and ribbed mussels (Geukensia denissa)". NEFSC Publicatin. Ww.nefsc.noaa.gov.

Eisler, R. (1987): "Polycyclic aromatic hydrocarbon hazards to fish, wildlife and invertebrates". A synoptic review: Laural, Md., Patuxent Wildlife Research Centre. U.S Fish and Wildlife Service. Biological Report, 85(1.11) pp81.

Geoge, S.G., Christiansen, J.S., Killies, B. and Wright. J (1995): "Dietary crude oil exposure during sexual maturation induces hepatic missed function oxygenase (CYPIA) activity at very low environmental temperatures in polar cod Boreogadus saiaa” Mar. Ecol. Prog. Ser. 122, 307-312.

Ghauch. A., Rima,. J., Fadchingeo, C., Suptil, J., and Martin - Bowger, M (2000): "Temperature phosphorescence analysis of PAHs using an imaging sensing system combined with a bifurcated optical filter and a cooled charge coupled device detector". Talanta. 51, $807-816$. 
Lockhart, W.L and Metner, D.A (1991): "Oil sensitive biomarker studies of fish from arctic Canada" AMOP. 14, $169-176$

Mauer, H.H (2007): "Analytical toxicology". Anal Bioanal Chem., 388:1311.

Ondo State Environmental Protection Agency (ODSEPA). (2000): "Report from the alleged crude oil spill on Ilaje communities, Ondo State". Chevron Nig. Ltd Ewan Production Platform, Final Report., July.

Rice, S.D. (1985): "Effects of oil on fish". In: Engelhard F.R (Ed), Petroleum effects in the Arctic environment, Else view Applied Science Publishers, Essex, England, pp $157-182$.

Sauer, T.C and Uhler, A.D (1994): “ Pollutant source identification: Advances in hydrocarbon fingerprinting”. Remediation, 5, 25-46.

Shi, Z., Tao, S., Pan, B., Liu, W., and Shem, W.R (2006). " Partitioning and source diagnostic of PAHs in rivers in Tianjin, China" Environ Pollut. 146(2), 492-500.

Stroomberg, G.J., Zappey, H., Steen, R.J., van Gestel, C.A., Ariese, F., Velthorst, N.H and Straalen, W.M (2004): "PAHs biotransformation in terrestrial invertebrates - a new metabolite in isopods and springtails". Comp Biochem Physiol Toxicol Pharmacol, 138 (2), 129 - 137.

Varanasi, U., Stein, J.E., Nishimoto, M (1989): "Biotranformation and disposition of PAHs in fish". In: U. Varanasi (Ed), metabolism of PAHs in the aquatic environment, CRC press Inc, Boca Raton FL, pp 93.

William, T.R., Susan, I.S and Donald, C.M. (1978): "The accumulation of low molecular weight aromatic hydrocarbons of crude oil by coho salmon (Ocorhynchus kisutch) ad starry flounder (Platichthys stellatus)" Arch. Environ. Contam. Toxicol. 7(1), 237-244. 